\title{
Peter Gemeinhardt
}

\section{Die Kirche und ihre Heiligen}

\author{
Studien zu Ekklesiologie und Hagiographie in der Spätantike
}

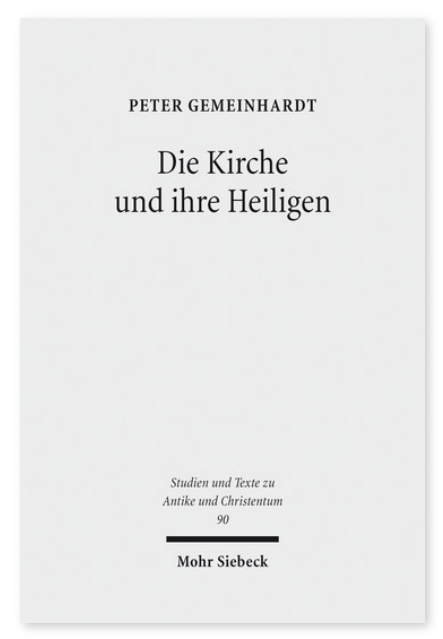

2014. VIII, 416 Seiten. STAC 90

ISBN 978-3-16-153554-3

DOI 10.1628/978-3-16-153554-3

eBook PDF $114,00 €$

ISBN 978-3-16-152717-3

fadengeheftete Broschur 114,00€
Peter Gemeinhardt nimmt in den vorliegenden Studien das spätantike Christentum als Institution und als Gemeinschaft der Heiligen in den Blick. Schwerpunkte liegen auf der Gestalt und dem Selbstverständnis der Kirche im 4. und 5. Jahrhundert und auf der Aktualität der Märtyrer auch nach dem Ende der Verfolgung, weiterhin auf der Bildung von Heiligen und schließlich auf der Vita Antonii und ihrem Verfasser Athanasius. Obwohl eine ausdrückliche theologische Reflexion der Kirche selten ist, wird intensiv diskutiert, was Kirche in der Spätantike sein soll: Volkskirche oder elitäre Gemeinschaft? Gemeinhardt verdeutlicht, dass zwar die Ränder der Kirche unscharf waren, dies aber dadurch ermöglicht wurde, dass die Kirche ein klares Zentrum hatte: das Leitbild der Märtyrer und der Heiligen. Diese fruchtbare Spannung von Offenheit und Bestimmtheit war für das Überleben und den Erfolg des Christentums in der Spätantike mit entscheidend.

Peter Gemeinhardt Geboren 1970; 1990-96 Studium der Ev. Theologie an den Universitäten Marburg und Göttingen; 2001 Promotion zum Dr. theol. an der Philipps-Universität Marburg; 2003 Ordination zum Pfarrer der Evangelischen Kirche von Kurhessen-Waldeck; 2006 Habilitation an der Friedrich-Schiller-Universität Jena; seit 2007 Lehrstuhlinhaber für Kirchengeschichte an der Georg-August-Universität Göttingen; 2015-20 Sprecher des Sonderforschungsbereichs »Bildung und Religion«; 2021-23 Dekan der Theologischen Fakultät.

https://orcid.org/0000-0003-3879-0397

Jetzt bestellen:

https://mohrsiebeck.com/buch/die-kirche-und-ihre-heiligen-9783161535543?no_cache=1

order@mohrsiebeck.com

Telefon: $+49(0) 7071-923-17$

Telefax: $+49(0) 7071-51104$ 